\title{
Obesity and Related Factors Among Children and Adolescents in Qatar
}

\author{
Mohammed Al-Thani ${ }^{1}$, Al-Anoud Al-Thani ${ }^{1}$, Walaa Al-Chetachi ${ }^{1}$, Hammad Akram ${ }^{\text {* }}$ \\ ${ }^{1}$ Ministry of Public Health, State of Qatar, Doha, Qatar
}

*Correspondence to

Dr. Hammad Akram, Ministry of

Public Health, State of Qatar, PO Box

42, Doha, Qatar

Tel: +974 44070912

Email: hakram@moph.gov.qa

Received September 27, 2017 Accepted October 24, 2017

Published online December 31, 2017

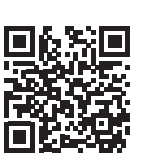

Please cite this article as follows: Al-Thani $\mathrm{M}, \mathrm{Al}$ Thani A, Al-Chetachi W, Akram H. Obesity and related factors among children and adolescents in Qatar. Int J Basic Sci Med. 2017;2(4):161165. doi:10.15171/ ijbms.2017.30.

\begin{abstract}
Overweight and obesity are major public health issues worldwide impacting millions of people. The prevalence of increased body weight among children and adolescents is becoming a global phenomenon. The State of Qatar is also experiencing the effects of obesity pandemic among adults and younger populations. In order to examine obesity and overweight parameters, a literature review was carried out using key scientific databases. Furthermore, this mini-review examines the selected factors that could be associated with obesity and overweight situation among children and adolescents living in Qatar. The results showed that the obesity is indeed a major public health issue among youth in Qatar.

Keywords: Qatar, Obesity, Overweight, Children, Adolescents
\end{abstract}

\section{Introduction}

Overweight and obesity continue to be major health problems globally. The proportion of adults with overweight and obesity has increased between 1980 and 2013 from $28.8 \%$ to $36.9 \%$ in men, and from $29.8 \%$ to $38.0 \%$ in women. Overweight and obesity are not problems of adult populations anymore. The World Health Organization (WHO) reports that the number of overweight or obese infants and young children (aged 0 to 5 years) has increased globally from 32 million in 1990 to 42 million in 2013. The same report shows that the prevalence of overweight and obesity in developed countries has increased since 1980 from $16.9 \%$ in boys and $16.2 \%$ in girls to $23.8 \%$ in boys and $22.6 \%$ in girls in 2013, respectively. Moreover, the developing countries have also observed the rising trend in overweight and obesity from $8.1 \%$ in 1980 to $12.9 \%$ in 2013 in boys and $8.4 \%$ to $13.4 \%$ in girls. ${ }^{1}$ This shows that overweight and obesity together have become a global issue rather than the issue of a certain geographical location or national socioeconomic profile. In North Africa and the Middle East region, the obesity prevalence was $8.4 \%$ in boys and $10.2 \%$ in girls in population less than 20 years old in $2013 .{ }^{1}$

There is evidence that the prevalence of overweight and obesity has increased over the years among children and adolescents in the Middle East region. ${ }^{2}$ The recent increase in obesity prevalence among children and adolescents in this region could be associated with the sedentary lifestyle, urbanization, increased income, family dietary patterns and family history. Furthermore, lack of physical activity, knowledge, and perception about different types of food categories along with their availability could be contributing towards obesity situation. The perception among parents that overweight is a sign of high social class, beauty, and prosperity could also be a challenge related to obesity management. Moreover, challenges associated with a lack of access to sports facilities, parks and weather conditions in the region may adversely impact on obesity situation. ${ }^{2}$

Prevalence of overweight and obesity is known to be high among adults living in the State of Qatar. ${ }^{3,4}$ Implementing population-based obesity prevention programs is essential for controlling the

(C) 2017 The Author(s); Published by Zabol University of Medical Sciences. This is an open-access article distributed under the terms of the Creative Commons Attribution License (http://creativecommons.org/licenses/by/4.0), which permits unrestricted use, distribution, and reproduction in any medium, provided the original work is properly cited. 
obesity situation in the region and country. The programs should include initiatives that can target teachers and parents in addition to the school children. Policy change and development of new guidelines could play critical roles in the sustainability of these programs. Community education on healthy dietary choices and the importance of physical activity can further supplement the existing programs.

Qatar is experiencing an increase in overweight and obesity situation not only in adults ${ }^{3,4}$ but also in children. This article provides the review of the available data on childhood and adolescent overweight and/or obesity situation among Qatari youth. The article also identifies key factors that could be responsible for the overweight and obesity situation in Qatar. The objective is also to provide recommendations and strategies to promote a healthier lifestyle and to reduce weight-related problems.

\section{Methods}

A review of existing data sources and articles was carried out. The literature search was performed on PubMed, Medline, Google Scholar, WHO reports and other local reports. The search was executed using keywords and phrases in the English language consisting of overweight, obesity, children, adolescents, cross-sectional surveys, and Qatar. The PubMed search produced 22 articles on childhood obesity and 40 articles on adolescent obesity in Qatar. The articles examining only clinical, pathobiological and surgical aspects pertaining to the obesity were excluded from the review. Only population-based studies or the ones exploring the prevalence of body weight disorders among children and adolescents were used and included. Four studies with primarily collected data were selected and 1 WHO population estimates report was also included in the review.

\section{Results and Discussion}

The review of the available data collected from Qatar on childhood and adolescent overweight and obesity situation is of concern. Examination of data from local studies along with the WHO estimates showed that over one-third of the children and youth in Qatar are obese and overweight together. According to the WHO estimates for Qatar, the standardized prevalence of obesity among 2 to 19 years old ranged between $15 \%$ to $20 \%$ during 1980 to $2013 .{ }^{1}$ Specifically, when we examined the data for residents in Qatar (less than 20 years old), 18.8\% of boys and $15.5 \%$ of the girls were estimated to suffer from obesity. ${ }^{1}$ Furthermore, the WHO data also revealed that $33.5 \%$ of boys and $22.1 \%$ of girls under the age of 20 years were overweight in Qatar. ${ }^{1}$ It was also found that in 2013, Qatar had a higher prevalence of obesity (boys 19\%, girls $15.5 \%)$ than the overall estimates of the Middle East and North Africa (MENA) region (boys $8.4 \%$, girls $10.2 \%$ ). ${ }^{1}$ In order to further examine the overweight/obesity situation in Qatar, we reviewed the results of population- based survey data (World Health Survey, Qatar 2006). The limitation of this data was the age limit of the samples which was less than 5 years old. Body mass index (BMI) was assessed using the $\mathrm{WHO}$ z-score criteria. ${ }^{5}$ The results showed that the prevalence of overweight and obesity was high. The data showed that $42.6 \%$ had a score between -1 and +1 , considered as a normal BMI range, while $28.7 \%$ had a high BMI for their age $(+1$ to $>+2)$. The boys were considerably more likely to have a higher BMI than girls, although the reverse was true for those in the category of +1 to +2 BMI z-scores. ${ }^{5}$

In 2014, Mamtani et al published the results of a study that examined the prediabetes situation among Qatari adolescents. ${ }^{6}$ The anthropometric measurements collected through this study were used for this review to share body weight situation among the samples. In a total sample of 1694 (boys and girls) between 11 to 18 years of ages, 25\% had obesity with a higher prevalence among boys (28\%) compared with girls (21\%). The results also showed that $23 \%$ of girls and $18 \%$ of boys were overweight. ${ }^{6}$

Al-Khateib et $\mathrm{al}^{7}$ published a study in 2013 which showed that $19 \%$ of 6 to 12 -year-old children (24\% boys, and $17 \%$ girls) were obese. Furthermore, about $20 \%$ of participants were found to be overweight (18.5\% boys and $21.3 \%$ girls). The study was based on a sample of 1500 children between the ages 6 and 12 years and collected from 23 schools using multistage random sampling approach. ${ }^{7}$ These results were consistent with an earlier study conducted in 2005 by Rizk et al in terms of overweight and obesity distribution by gender among 6 to 11 year old children. ${ }^{8}$ Rizk et al showed that about $22 \%$ of boys and $17 \%$ of girls were obese and $10 \%$ of boys and $17 \%$ of girls were overweight (total $31.7 \%$ of boys and $32.7 \%$ of girls were overweight or obese). ${ }^{8}$ The same study found that the overweight and obese children also had a significantly increased risk of a larger waist circumference, hypertriglyceridemia, low HDL, and high atherogenic index compared with the children who were not overweight or obese. ${ }^{8}$ The study concluded that the children who were obese or overweight were predisposed to heart diseases later during adulthood. ${ }^{8}$ In another study published in 2011 by Rizk et al $(n=67$, children aged 6 to 12 years old recruited from an outpatient pediatric clinic in 2005), ${ }^{8}$ the overall prevalence of metabolic syndrome (MeS) according to NCEP-III criteria was $3.0 \%$. The prevalence of $\mathrm{MeS}$ was $9.5 \%$ among overweight and obese participants. ${ }^{9}$ The study showed a significant prevalence of MeS and associated features among overweight and obese children. ${ }^{9}$

Table 1 provides the summary of the findings from the above-mentioned studies.

The Global School-Based Student Health Survey- Qatar 2011 (13 to 15-year-old students) provides some of the risk factors that can contribute to overweight and obesity. ${ }^{10}$ The survey reported that $55.4 \%$ of the girls and $43.6 \%$ of the boys spent 3 or more hours per day performing sitting activities during a typical day. Furthermore, $62.5 \%$ of 
Table 1. Summary of the Reviewed Studies Providing Data on Obesity and Overweight in the State of Qatar

\begin{tabular}{|c|c|c|c|c|c|c|}
\hline Source & Sample & Year & Indicator & Age & Overweight & Obese \\
\hline WHO & Estimates & 1980-2013 & $\begin{array}{l}\text { Age Standardized Prevalence } \\
\text { Percent }\end{array}$ & $2-19$ years & $\begin{array}{l}\text { Male; } 33.5 \% \\
\text { Female; } 22.1 \%\end{array}$ & $\begin{array}{l}\text { Male; } 18.8 \% \\
\text { Female; } 15.5 \%\end{array}$ \\
\hline $\begin{array}{l}\text { World Health } \\
\text { Survey-Qatar }\end{array}$ & 770 & 2006 & BMI z-scores/WHO criteria & $<5$ years & $\begin{array}{l}\text { Overall; } 12.6 \% \\
\text { Male; } 9.7 \% \\
\text { Female; } 15.5 \%\end{array}$ & $\begin{array}{l}\text { Overall; } 16.1 \% \\
\text { Male; } 18.4 \% \\
\text { Female; } 13.6 \%\end{array}$ \\
\hline Mamtani et al & 1694 & $\begin{array}{l}2012 \text { (published in } \\
\text { 2014) }\end{array}$ & $\begin{array}{l}2007 \text { WHO growth reference } \\
\text { data }\end{array}$ & $11-18$ years & $\begin{array}{l}\text { Male; } 18 \% \\
\text { Female; } 23 \%\end{array}$ & $\begin{array}{l}\text { Overall; } 25 \% \\
\text { Male; } 28 \% \\
\text { Female; } 21 \%\end{array}$ \\
\hline Al-Kateib et al & 1500 & Published 2013 & WHO criteria & $6-12$ years & $\begin{array}{l}\text { Overall; } 20 \% \\
\text { Male; } 18.5 \% \\
\text { Female; } 21.3 \%\end{array}$ & $\begin{array}{l}\text { Overall; } 19 \% \\
\text { Male; } 24 \% \\
\text { Female; } 17 \%\end{array}$ \\
\hline Rizk et al & $\begin{array}{l}315 \text { (Qataris } \\
\text { only) }\end{array}$ & $\begin{array}{l}2005 \text { (published in } \\
2012 \text { ) }\end{array}$ & $\begin{array}{l}\text { International Obesity Task } \\
\text { Force (IOTF) reference values }\end{array}$ & $6-11$ years & $\begin{array}{l}\text { Male; } 9.8 \% \\
\text { Female; } 17.2 \%\end{array}$ & $\begin{array}{l}\text { Male; } 21.9 \% \\
\text { Female } ; 16.9 \%\end{array}$ \\
\hline
\end{tabular}

students (60\% boys, $64.8 \%$ girls) drank carbonated soft beverages 1 or more times per day during the past 30 days. Moreover, $11.7 \%$ consumed carbonated soft drinks 5 or more times per day. In terms of physical activity, only $15 \%$ of survey participants were appropriately active, i.e. at least $60 \mathrm{~min} / \mathrm{d}$ for 5 or more days per week. While examining dietary habits, we found that only $25 \%$ of students were meeting the recommended 5 servings of fruit and vegetable consumption requirement per day. Furthermore, $42 \%$ of the participants ate fast food 3 or more days a week. Only $37 \%$ of students had breakfast most of the times during the month. ${ }^{10}$

Recently collected data (Growth Monitoring Program data 2015-2016) of 168011 students from 296 private and government schools in Qatar shows that among 5-11 years old students, $20.5 \%$ were found to be obese (boys 23\%, girls $17.9 \%$, Qatari 23.3\%, non-Qatari 19\%) while among $12-17$ age group, $23.1 \%$ had obesity (boys $27.1 \%$, girls 19\%, Qatari 28.3\%, non-Qatari 19.5\%). Twenty percent of 5-11 year olds were overweight (boys 18.9\%, girls 21.1\%, Qatari 18.5\%, non-Qatari 20.7\%) while 23\% of students in age group 12-17 were overweight (boys 22.5\%, girls 23.7\%, Qatari 22.4\%, non-Qatari 23.6\%). This surveillance data was collected during academic year 2015-2016 as a part of the Growth Monitoring Program and Qatar's National Nutrition and Physical Activity Action Plan 2011-2016.

While examining the gender differences among various studies mentioned above, we found that with the exception of the WHO estimates, ${ }^{1}$ in all the other studies females had a higher prevalence of overweight status while males had higher obesity prevalence. These results are consistent with the findings from other regional studies. For instance, the data collected from a study in Kuwait showed that the overall prevalence of overweight and obesity was $19.8 \%$ and $26.2 \%$, respectively, and obesity was significantly more common among boys compared with girls. ${ }^{11}$ Similarly, in a study in Bahrain, a high prevalence of overweight (13.5\%) was found among females versus boys $(9.1 \%)$ contrary to a high prevalence of obesity among boys (12.3\%) versus girls (11.9\%). ${ }^{12}$ In neighboring Saudi Arabia, El Mouzan et al also found that the prevalence of overweight was higher among girls compared with boys. ${ }^{13}$

If we examine the $\mathrm{WHO}$ estimates, the obesity prevalence has increased from $17.1 \%$ in 1980 to $18.8 \%$ in 2013 among males less than 20 years of age. In the same time frame and among same age category, obesity among females also increased from $12.4 \%$ to $15.5 \%{ }^{1}$ Based on the results of the population-based surveys in Qatar, 32\% (40\% Qatari, $28 \%$ non-Qatari) of the adult population were obese in 2006 while $41.4 \%$ (only Qataris) were identified to be obese in $2012 .{ }^{3,5}$

The attitudes of the adult household members can have an impact on the weight of younger household members, e.g. types and frequency of food consumption in a household, and family members' lifestyle, how sedentary or physically active they are, can also have an influence on children ${ }^{14}$ and adolescents. According to the data from Qatar National STEPwise survey (2012), about 70\% of Qatari residents between the ages of 18 and 64 were overweight (28.7\%) and obese (41.4\%), and $46 \%$ had low levels of physical activity and $91 \%$ of residents were consuming less than 5 servings of fruit and vegetables per day. ${ }^{15}$ These characteristics can have a great influence on children and adolescents in a Qatari household. Furthermore, Qatar Household Income and Expenditure Survey (HIES) (2012/2013) provided a food pattern based on the different types of food purchased in the State of Qatar. ${ }^{16}$ Energy pattern revealed that Fat/Energy ratio was $>35 \%$, which is considered high, according to WHO recommendations (15\%-30\%). ${ }^{16}$ Some of the key findings from the survey were as follows:

- Dietary energy pattern of food purchased at household level for free sugars was $13.9 \%$, greater than the recommended $<10 \%$.

- $\quad$ About two-thirds of beverages pattern (62\%) were in carbonated form while the rest $(38 \%)$ were in the 
form of juice.

- Fiber consumption was very low, i.e. 2.0 while recommended level (density per $1000 \mathrm{kcal}$ ) is 8-20.

- Energy content for daily purchased food per person for the total sample was $3676 \mathrm{kcal} /$ capita/day compared to the estimated requirement of 2143 , for Qatari it was $4275 \mathrm{kcal} /$ capita/day (estimated requirement 2157) and $2424 \mathrm{kcal} /$ capita/day for Non-Qatari (estimated requirement 2113.7).

Breastfeeding is considered a critical factor in the development of childhood obesity. A meta-analysis showed that the breastfeeding had a significant role in reducing the risk of obesity in children. ${ }^{17} \mathrm{~A}$ study in Qatar with 770 Arab mothers attending primary health care centers in the State of Qatar (approximately half Qatari and half non-Qatari) revealed that the early initiation of breastfeeding was observed in $57 \%$ of the participants while exclusive breastfeeding under 6 months was $18.9 \% .{ }^{18}$ In another study that was conducted in 2012 (The Qatar Multiple Indicator Cluster Survey 2012) with a sample comprising 2082 Qataris and non-Qataris under 5 years of age showed that less than $50 \%(\sim 47 \%)$ of 0 to 1 month old infants were exclusively breastfed. ${ }^{19}$ At 2 to 3 months of age, the percentage declined to about 39\%. By the sixth month, the percentage of infants that were exclusively breastfed was $29 \%$, far higher than what was demonstrated in the results of the study by Khoji et al noted above. ${ }^{18,19}$

\section{Conclusions and Recommendations}

It is clearly evident from this short review that the overweight and obesity together are the matters of concern. The findings from this article along with the future scientific studies could be used to support policies, public health programs, and public engagement initiatives. This includes the use of evidence-based (targeted) interventions and approaches through policy and guidelines. Furthermore, enhancing school-based health education programs targeting students and involving parents, teachers and other school staff could be used to address issues at upstream and downstream levels. Multi-sectoral collaborations could play an important role in sustaining programs, increasing health surveillance, disseminating information and eventually implementing evidence-based strategies. Educational initiatives using diverse communication methods such as social and electronic media, community and mediabased campaigns, workshops, training and face to face counseling to promote healthy behaviors are other ways to teach community at a wider level. Teaching parents could be critical in improving their understanding of the appropriate growth and development milestones of children specifically targeting their perception about body weight, eating habits and so on. Other approaches could include introducing more venues and creating opportunities for students to engage in physical activity, intensive behavior change interventions, training healthcare workers and expanding preventive health services. ${ }^{20}$ Furthermore, using globally recognized best practices, the research initiatives can be implemented to examine sedentary behavior (screen time, sitting times at schools, time spent in cars, etc.) and related determinants and eventually design appropriate interventions. ${ }^{19}$

\section{Ethical Approval}

Not applicable.

\section{Competing Interests}

There is no conflict of interest to declare.

\section{References}

1. Ng M, Fleming T, Robinson $\mathrm{M}$, et al. Global, regional, and national prevalence of overweight and obesity in children and adults during 1980-2013: a systematic analysis for the Global Burden of Disease Study 2013. Lancet. 2014;384(9945):766-781. doi:10.1016/s01406736(14)60460-8

2. Abdul-Rasoul MM. Obesity in children and adolescents in Gulf countries: Facts and solutions. Avances en Diabetología. 2012;28(3):64-69. doi:10.1016/j.avdiab.2012.04.001

3. Al-Thani $\mathrm{MH}$, Al-Thani AA, Al-Chetachi WF, et al. Dietary and nutritional factors influencing obesity in Qatari adults and the modifying effect of physical activity. J Obes Weight Loss Medicat. 2015;1:1-7.

4. Al-Thani MH, Al-Thani AAM, Al-Chetachi WF, et al. Situation of Diabetes and Related Factors Among Qatari Adults: Findings From a Community-Based Survey. JMIR Diabetes. 2017;2(1):e7. doi:10.2196/diabetes.7535

5. World Health Survey, Qatar 2006. Doha, Qatar: Supreme Council of Health; 2006.

6. Mamtani R, Lowenfels AB, Sheikh J, et al. Adolescent prediabetes in a high-risk Middle East country: a crosssectional study. JRSM Open. 2014;5(8):2054270414536550. doi: $10.1177 / 2054270414536550$

7. Abdallah MA, Al-Zoghbi M, Saleh M, Qotba H. Influence of Sedentary Lifestyle on Body Weight in Qatari School Children. Qatar Foundation Annual Research Forum Proceedings. 2012:BMP127. doi:10.5339/qfarf.2012. BMP127

8. Rizk NM, Yousef M. Association of lipid profile and waist circumference as cardiovascular risk factors for overweight and obesity among school children in Qatar. Diabetes Metab Syndr Obes. 2012;5:425-432. doi:10.2147/dmso. s39189

9. Rizk N, Amin M, Yousef M. A pilot study on metabolic syndrome and its associated features among Qatari schoolchildren. Int J Gen Med. 2011;4:521-525. doi:10.2147/ijgm.s21103

10. National Center for Chronic Disease Prevention and Health Promotion. Global School-Based Student Health Survey Results. Qatar; 2011. http://www.who.int/chp/gshs/ qatar/en/.

11. State of Kuwait, Ministry of Health. The Kuwait Nutrition Surveillance System. https://www.moh.gov.kw/en/ 
Ministry-Statistics. Published 2015.

12. Gharib NM, Rasheed P. Obesity among Bahraini Children and Adolescents: Prevalence and Associated factors. J Bahrain Med Soc. 2008;20(3).

13. El Mouzan MI, Foster PJ, Al Herbish AS, et al. Prevalence of overweight and obesity in Saudi children and adolescents. Ann Saudi Med. 2010;30(3):203-208. doi:10.4103/02564947.62833

14. Sahoo K, Sahoo B, Choudhury AK, Sofi NY, Kumar R, Bhadoria AS. Childhood obesity: causes and consequences. J Family Med Prim Care. 2015;4(2):187192. doi:10.4103/2249-4863.154628

15. Chronic Disease Risk Factor Surveillance: Qatar STEPS report 2012. Qatar: The Supreme Council of Health. https://www.moph.gov.qa/.

16. Al-Thani M, Al-Thani AA, Al-Mahdi N, et al. An Overview of Food Patterns and Diet Quality in Qatar: Findings from the National Household Income Expenditure Survey.
Cureus. 2017;9(5):e1249. doi:10.7759/cureus.1249

17. Yan J, Liu L, Zhu Y, Huang G, Wang PP. The association between breastfeeding and childhood obesity: a meta-analysis. BMC Public Health. 2014;14:1267. doi:10.1186/1471-2458-14-1267

18. Al-Kohji S, Said HA, Selim NA. Breastfeeding practice and determinants among Arab mothers in Qatar. Saudi Med J. 2012;33(4):436-443.

19. Qatar Statistics Authority, Supreme Council of Health, UNICEF. Qatar Multiple Indicator Cluster Survey: Preliminary Findings. Doha: Qatar Statistics Authority; 2012.

20. Mabry R, Koohsari MJ, Bull F, Owen N. A systematic review of physical activity and sedentary behaviour research in the oil-producing countries of the Arabian Peninsula. BMC Public Health. 2016;16(1):1003. doi:10.1186/s12889 016-3642-4 